\title{
A protocol to isolate and qualify purified human preantral follicles in cases of acute leukemia, for future clinical applications
}

\author{
Elodie Mouloungui ${ }^{1}$, Tristan Zver ${ }^{1,3}$, Christophe Roux ${ }^{1,2,3}$ and Clotilde Amiot ${ }^{1,2,3^{*}}$
}

\begin{abstract}
Background: Autotransplantation of cryopreserved ovarian cortex can be associated with a risk of cancer cell reseeding. This issue could be eliminated by grafting isolated preantral follicles. Collagenase NB6 is an enzyme produced under good manufacturing practices (GMP) in compliance with requirements for tissue engineering and transplantation in humans and thus can be used to isolate preantral follicles from ovarian tissue in the framework of further clinical applications. Multicolor flow cytometry is an effective tool to evaluate the potential contamination of follicular suspensions by leukemic cells.
\end{abstract}

Methods: The efficiency of collagenase NB6 was evaluated in comparison to collagenase type IA and Liberase DH, in terms of yield, morphology and viability. A short-term in vitro culture of follicles isolated with collagenase NB6 was conducted for 3 days in a fibrin matrix. A modelization procedure was carried out to detect the presence of leukemic cells in follicular suspensions using multicolor flow cytometry (MFC).

Results: No statistical differences were found between collagenase NB6, Liberase DH $(p=0.386)$ and collagenase type IA $(p=0.171)$ regarding the number of human preantral follicles isolated. The mean diameter of isolated follicles was significantly lower with collagenase NB6 $(p<0.0001)$. The survival rate of isolated follicles was $93.4 \%$ ( $n=272)$ using collagenase NB6 versus $94.9 \%(n=198)$ with Liberase DH and $92.6 \%(n=298)$ using collagenase type IA. Even after 3 days of in vitro culture in a fibrin scaffold, most of the isolated follicles were still alive after using collagenase NB6 (90.7\% of viable follicles; $n=339)$. The rate of isolated Ki67-positive follicles was $29 \pm 9.19 \%$ before culture and $45 \pm 1.41 \%$ after 3 days. In 23 out of 24 follicular suspensions analyzed, the detection of leukemic cells by MFC was negative. The purification had no significant impact on follicle viability.

Conclusion: The isolation and purification of human preantral follicles were performed following good manufacturing practices for cell therapy. Multicolor flow cytometry was able to confirm that final follicular suspensions were free from leukemic cells. This safe isolation technique using collagenase NB6 can be considered for future clinical applications.

Keywords: Collagenase NB6, Good manufacturing practices, Human follicle isolation, Leukemic cell purification

\section{Background}

Over the past 30 years, the survival rate of cancer patients has drastically improved thanks to early diagnosis, advances in surgery procedures and adjuvant therapies $[1,2]$. Due to their toxicity, chemo- and radio-therapies can lead to side

\footnotetext{
* Correspondence: clotilde.amiot@univ-fcomte.fr

${ }^{1}$ University Bourgogne Franche-Comté, INSERM, EFS BFC, UMR1098,

Interactions Hôte-Greffon-Tumeur/Ingénierie Cellulaire et Génique, F-25000

Besançon, France

${ }^{2}$ INSERM CIC-1431, University Hospital of Besançon, Clinical Investigation

Center in Biotherapy, F-25000 Besançon, France

Full list of author information is available at the end of the article
}

effects that affect the quality of life of those patients. Indeed, the risk of premature ovarian failure and infertility is important and varies depending on the age of the patient, type of drug, drug dose, protocol used, treatment duration and disease severity [3, 4]. For women diagnosed with cancer, desire to have a child is a major concern [5]. For this reason, techniques of fertility preservation have gained interest. Ovarian tissue cryopreservation is one of the available options to preserve fertility in women when the administration of a highly gonadotoxic treatment cannot be delayed and for prepubertal girls [6,7]. Currently the re-use 
of frozen/thawed ovarian tissue, which can only be performed by autograft, has led to more than a hundred live births worldwide $[7,8]$.

However, in some cases of malignant disease, ovarian tissue transplantation is associated with a high risk of cancer reseeding [9-13]. The most common cancer in prepubertal girls is leukemia, with acute lymphoblastic leukemia (ALL) and acute myeloid leukemia (AML) accounting for 85 and 15\% of cases, respectively [2]. Real time quantitative polymerase chain reaction (RT-qPCR) $[10,14]$, multicolor flow cytometry (MFC) [15-18] and ovarian tissue xenografts in immunodeficient mice [11, 19] are techniques proposed for the detection of minimal residual disease (MRD) in cryopreserved ovarian tissue.

Several alternatives to autograft of frozen/thawed ovarian tissue, such as the development of an engineered artificial ovary using mainly fibrin or alginate scaffolds [19-28], or in vitro folliculogenesis [29-39], were investigated based on the use of isolated preantral follicles, mostly primordial follicles. Primordial follicles are encapsulated in a basement membrane of collagen IV, laminin and to a lesser extent fibronectin [40]. Culturing isolated follicles separates them from surrounding stromal elements like capillaries, white blood cells and nerves and thus protects them from the risk of contamination with malignant cells, as cancerous cells are not located inside follicles but in the stroma [41].

In order to isolate follicles, techniques that consist of mechanical and/or enzymatic digestion of human cryopreserved ovarian tissue have been developed [37, 38, 42-45]. For clinical purposes, a highly-purified enzyme, free of endotoxins, must be used. Lierman et al., have compared the efficiency of Liberase DH, a purified good manufacturing practices (GMP) grade blend enzyme, to the first generation of Liberases (Liberase TM) and to collagenase IV [46]: these authors showed that Liberase DH allows isolation of viable primordial and primary follicles of higher quality and with good morphology and no sign of apoptosis, but the follicular yield was lower with Liberase DH than collagenase IV. Collagenases NB1 and NB6 are blends of GMP grade enzymes, which have been validated for their clinical applications; the highly purified collagenase NB1 has been used to isolate human pancreatic islets. When comparing the efficiency of Liberase DH and collagenase NB1, isolation yield and purity were found to be significantly higher with collagenase NB1, and in vitro function was well preserved [47]. Collagenase NB6, which is composed of collagenase type I and II, has also successfully been used in a clinical-grade protocol for the isolation of human umbilical cord tissue cells [48]. GMP grade collagenases NB1 and NB6 have shown their efficiency in different types of tissue but have not yet been tested for human ovarian follicle isolation.

Before considering the use of isolated human primordial follicles in patients with a risk of cancer reseeding, we have to ensure that the suspension containing isolated follicles is free of malignant cells. Soares et al., have developed a model of artificial addition of leukemic cell lines to suspensions obtained from ovarian cortical strip dissociation [42]. RT-qPCR was performed using the molecular marker BCR$\mathrm{ABL}$ to detect the risk of ovarian residual disease. Even though few leukemic cells were retrieved during follicle pickup, they showed that three washes were sufficient to reduce the amount of leukemic cells detected in ovarian suspensions as the RT-qPCR was negative in all cases. In a recent study, Soares et al. found that $66 \%$ of malignant cells were present in cryopreserved ovarian tissue from 9 leukemia patients [49]. However, they confirmed by RTqPCR analyses that three washes were able to eradicate malignant cells in follicular suspensions obtained from cryopreserved ovarian tissue of leukemia patients.

Multicolor flow cytometry (MFC), based on leukemic cell immunophenotype detection, is the only applicable technique when molecular markers are not available, and thus could be potentially applied to all leukemic patients [17]. MFC is able to detect one positive cell, but in hematology a significant abnormal cell population is defined as a homogeneous cluster of at least 20 LAIP+ (Leukemia-Associated ImmunoPhenotype positive) cells, referring to the common cut-off level used for the assessment of minimal residual disease in blood or bone marrow [50].

The aim of our study was first to evaluate the efficiency, in term of follicle yield, proliferation and viability, of an isolation technique using the highly purified GMP grade blend enzyme collagenase NB6, and second to ensure that the ovarian suspension containing isolated follicles is free of malignant cells after the initial addition of leukemic cells using MFC.

\section{Methods \\ Collection of ovarian tissue}

Ovarian biopsies (weight: mean $=63.36 \pm 30.49 \mathrm{mg}$; range $=13.9-171.2 \mathrm{mg} ; n=43)$ were obtained from 16 women aged between 25 and 37 (mean age $=29.88$ years) undergoing laparoscopic ovarian drilling for polycystic ovary syndrome. Human ovarian tissue obtained from laparoscopic drilling performed for treatment of women suffering from polycystic ovary syndrome has been used as reference tissue for our research for several years [51]. Ovarian cortical fragments were obtained using biopsy grasping forceps from an avascular portion of the ovary, before electrocoagulation of the puncture site. Specimens were then immediately transported to the laboratory in Leibovitz L-15 medium (Eurobio, France) on ice.

\section{Freezing/thawing of ovarian tissue}

Cortical fragments were transferred in $1.8 \mathrm{ml}$ cryovials (VWR, France) containing $1.5 \mathrm{ml}$ of a freezing solution 
composed of $1.5 \mathrm{M}$ dimethyl sulfoxide (DMSO; Sigma Aldrich, France) and 0.1 M sucrose (Pharmacy of Besançon University Hospital, France) in Leibovitz L-15 supplemented with $10 \%$ decomplemented $\mathrm{AB}$ human serum (Etablissement Francais du Sang, Bourgogne FrancheComté, France). Frozen/thawed $\mathrm{AB}$ human serum was obtained from consenting male donors. Decomplementation was carried out by a 30 -min incubation at $56{ }^{\circ} \mathrm{C}$, and the decomplemented $\mathrm{AB}$ human serum obtained was then stored at $4{ }^{\circ} \mathrm{C}$.

Cortical fragments in freezing solutions were incubated for $30 \mathrm{~min}$ on ice while gently rotated. Cortical biopsies were frozen according to a protocol using slow cooling with manual seeding in a programmable freezer (Planer ${ }^{\circ}$ 360 or 560; Cryobiosystem, France) and stored in liquid nitrogen [51].

Cortical fragments were thawed according to a protocol previously described in the laboratory [52]. Briefly, the cryovials were warmed for $5 \mathrm{~min}$ in a heat chamber at $37^{\circ}$ $\mathrm{C}$, ovarian tissue pieces were then washed in decreased solutions of DMSO $1.5 \mathrm{M}$ (5 min), $1 \mathrm{M}$ (5 min), $0.5 \mathrm{M}$ (10 min) containing $0.05 \mathrm{M}$ sucrose in Leibovitz L-15 supplemented with $10 \%$ decomplemented $\mathrm{AB}$ human serum. Ovarian tissue strips were finally transferred to a solution of Leibovitz L- $15^{\circ}$ supplemented with $20 \%$ of decomplemented $\mathrm{AB}$ human serum, for 10 more minutes.

\section{Ovarian tissue dissociation}

This technique, previously published by our team [51], was modified as described below. Cortical fragments were cut into small pieces of $\sim 1 \mathrm{~mm}^{3}$ and placed in a cryovial containing the enzymatic solution. They underwent mechanical and enzymatic dissociation using either collagenase IA routinely used in our laboratory $(200 \mathrm{IU} / \mathrm{ml}$ final, Sigma Aldrich), a GMP grade purified collagenase NB6 (200 IU/ml final, Serva Electrophoresis GMbH; Coger, France), or Liberase DH (0.28 Wünsch U/ml, Roche, France).

Fragments dissociated with collagenase IA or collagenase NB6 were incubated for $3 \mathrm{~h}$ in a heat chamber at $37^{\circ} \mathrm{C}$ and vortexed every $30 \mathrm{~min}$. The collagenase activity was inhibited by the addition of $30 \%$ decomplemented $\mathrm{AB}$ human serum. The ovarian cell suspension obtained was filtered through a $60 \mu \mathrm{m}$ nylon filter (Fisher Scientific, France).

The protocol for tissue dissociation with Liberase DH was a modification of the protocol described by Vanacker et al. [43]. Fragments dissociated with Liberase DH were incubated for $90 \mathrm{~min}$ in a heat chamber at $37{ }^{\circ} \mathrm{C}$ with gentle agitation. The collagenase activity was inhibited by the addition of $30 \%$ decomplemented $\mathrm{AB}$ human serum.

\section{Freezing/thawing of leukemic cells}

Frozen/thawed blood or bone marrow (BM) cells originating from acute lymphoid leukemia (ALL) and acute myeloid leukemia (AML) patients $(n=8)$, with known LAIP, were used for serial dilutions of leukemic cells in ovarian cell suspensions obtained from healthy ovarian cortical strips. Blood or bone marrow cells were collected at diagnosis, frozen and stored in liquid nitrogen. Leukemic cells were thawed at $37{ }^{\circ} \mathrm{C}$ for $5 \mathrm{~min}$, then added dropwise to a solution containing $10 \mathrm{ml}$ of RPMI 1640 GlutaMax (Invitrogen, Cergy-Pontoise, France) supplemented with $20 \%$ fetal bovine serum (PAN Biotech $\mathrm{GmbH}$, Aidenbach, Germany). The solution was then incubated for $15 \mathrm{~min}$ at $37^{\circ} \mathrm{C}$ and centrifugated at $300 \mathrm{~g}$ for $7 \mathrm{~min}$. Finally, the pellet was resuspended in RPMI 1640 GlutaMax supplemented with $20 \%$ fetal bovine serum for cell counting.

\section{Marking of leukemic cells using a cell tracer}

Thawed leukemic cells were resuspended with $5 \mu \mathrm{M}$ of CFDA SE Cell tracer (Vybrant ${ }^{\circ}$ CFDA SE Cell Tracer Kit, Life Technologies SAS, France) as described by Soares et al., [42]. The CFDA SE Cell tracer allows for the labeling of leukemic cells in ovarian suspensions, with an inverted fluorescence microscope (CKX41, Olympus, France) by an intense green staining (ex/em: 492/ $517 \mathrm{~nm}$ ). The observation of stained leukemic cells was performed punctually as a control of the isolation technique.

\section{Addition of leukemic cells in an ovarian cell suspension}

An initial addition of leukemic cells was made to obtain a first ovarian cell suspension with an excess of either $10^{6}$ or $10^{5}$ leukemic cells, depending on the total leukemic cells available after count. From this first suspension, 1/10 dilutions were made twice to obtain decreasing concentrations of leukemic cells in ovarian cell suspensions containing isolated follicles (we thus obtained three ovarian cell suspensions containing either $10^{6}, 10^{5}$, and $10^{4}$ leukemic cells or $10^{5}, 10^{4}$ and $10^{3}$ leukemic cells). The amount of leukemic cells added to ovarian suspensions was defined so as to achieve a sensitivity to an order of $10^{-5}$, which is comparable to the threshold of sensitivity for minimal residual disease detection by multicolor flow cytometry [17]. The remaining solution of leukemic cells was used as positive control of the experiment.

\section{Follicle isolation and purification}

The three resulting ovarian cell suspensions containing isolated follicles and leukemic cells were transferred to a Petri dish (IVF ICSI Nunc ${ }^{\text {Th }}$ dish, $35 \times 10 \mathrm{~mm}$, Thermo Scientific, France) containing $100 \mu \mathrm{l}$ of in vitro fertilization medium (IVF ${ }^{\mathrm{m}}$, Vitrolife, France) under oil (Ovoil ${ }^{\mathrm{Tm}}$, Vitrolife, France). Isolated follicles were then manually picked up using a denudation pipette with an inner diameter of $130 \mu \mathrm{m}$ (Vitrolife, France) and transferred to an IVF 4well cell culture plate $\left(\mathrm{Nunc}^{\mathrm{Tm}}\right.$, ThermoFisher Scientific, France), each well containing $30 \mu \mathrm{l}$ of IVF medium under 
oil. The denudation pipette was changed after each dilution group was transferred. Follicles were washed 3 times in fresh IVF medium droplets, as described by Soares et al., [42]. The remaining droplet from the first pipetting of follicles (no wash) in the first well and the last drop containing washed isolated follicles in the fourth well (after 3 washes) were analyzed by MFC. Isolated follicles were manually counted using the Fertimorph ${ }^{\mathrm{Tm}}$ vision software on a micromanipulation station (Research Instruments, France) under bright field, with a Hoffman modulation contrast objective (Nikon, France).

\section{Formation of a fibrin scaffold}

The protocol used for the formation of a fibrin scaffold was a modification of the one previously described by Paulini et al. [53]. Evicel ${ }^{\odot}$ is a fibrin sealant kit, routinely used in surgery and approved for clinical applications (Evicel ${ }^{\bullet}$, Ethicon, France), which contains a solution of human fibrinogen (70 mg/ml) and a solution of human thrombin (1000 IU/ $\mathrm{ml}$ ). The stock solution of fibrinogen was diluted in alphaminimum essential medium ( $\alpha \mathrm{MEM}$, Sigma Aldrich, France) to obtain a final concentration of $50 \mathrm{mg} / \mathrm{ml}$. Meanwhile, a stock solution of thrombin was also diluted in $\alpha M E M$ to obtain a final concentration of $10 \mathrm{IU} / \mathrm{ml}$. A droplet of $15 \mu \mathrm{l}$ of fibrinogen was placed in a 4-well cell plastic culture plate in which 30 to 100 preantral follicles isolated with GMP grade collagenase NB6 were carefully placed. No prior filtration step was carried out on ovarian suspensions from which isolated follicles would be embedded in fibrin matrices. The droplet containing isolated follicles was then mixed with $15 \mu \mathrm{l}$ of thrombin solution. The resulting droplet of $30 \mu \mathrm{l}$ was finally incubated $45 \mathrm{~min}$ at $37{ }^{\circ} \mathrm{C}$ to allow the fibrin to polymerize.

\section{In vitro culture of isolated follicles embedded in a fibrin scaffold}

Fibrin scaffolds were submerged with $\sim 200 \mu$ l of culture medium made up of aMEM supplemented with $10 \%$ decomplemented $\mathrm{AB}$ human serum, $10 \mu \mathrm{g} / \mathrm{ml}$ insulin, $5 \mu \mathrm{g} / \mathrm{ml}$ transferrin and $5 \mathrm{ng} / \mathrm{ml}$ sodium selenite (ITS supplement, Sigma Aldrich, France), and then incubated up to 3 days at $37{ }^{\circ} \mathrm{C} / 5 \% \mathrm{CO}_{2}$. Half of the medium was changed the second day of culture with fresh prewarmed supplemented culture medium.

\section{Viability assessment}

The initial health of isolated follicles was evaluated using trypan blue staining. Follicular suspensions were exposed to a $0.4 \%$ trypan blue solution (Sigma Aldrich, France) for $10 \mathrm{~min}$. Dead follicles appeared in blue, and live ones were unstained after exposure to trypan blue staining [51].

Follicle viability was then assessed using a Live/Dead viability assay kit as described in the manufacturer's protocol (Live/Dead ${ }^{\oplus}$ viability assay kit for mammalian cells, Life Technologies SAS, France). Briefly, isolated follicles were incubated in $30 \mu \mathrm{l}$ of phosphate-buffered saline 1X (PBS; Cambrex, Belgique) containing $4 \mathrm{mM}$ calcein AM and $2 \mathrm{mM}$ ethidium homodimer-1 for $30 \mathrm{~min}$ at room temperature in the dark. After exposure to fluorescent dyes, follicles were observed under an inverted fluorescence microscope (CKX41, Olympus, France). Green fluorescence was visualized in live cells (ex/em: $\sim 494 / \sim 517 \mathrm{~nm}$ ) and red fluorescence in dead cells (ex/em: 528/ 617 nm). Pictures were taken with a Moticam Pro 282S camera (Motic, Hong Kong).

Isolated follicles were classified in four categories depending on the percentage of dead granulosa cells: V1, living follicles: follicles with the oocyte and all the granulosa cells viable (stained green); V2, minimally damaged follicles: follicles with less than $10 \%$ of granulosa cells dead (stained red); V3, moderately damaged follicles: follicles with $10-50 \%$ of granulosa cells dead; V4, dead follicles: follicles with the oocyte or over $50 \%$ of granulosa cells dead [54].

\section{Measurement of follicle diameter}

Follicle diameters were calculated from measurements of isolated preantral follicles areas on images taken right after isolation and also after in vitro culture, using NIS software (NIS-Elements D 4.00.00, Nikon, France). Only follicles with the characteristic shape were considered. The basement membrane of follicles was taken as their outer limit. The follicle diameter was based on surface area measurement and computation of the theoretical diameter.

\section{Immunocytochemistry}

Fibrin scaffolds $(n=4)$ were fixed in formol $4 \%$ for $24 \mathrm{~h}$, dehydrated and embedded in paraffin. They were then cut with a rotary microtome (HM 340E, Microm Microtech, France) into $7 \mu \mathrm{m}$ sections. Every five sections, slides were stained with hematoxylin-eosin (RAL Diagnostic, France) in order to confirm the presence of isolated follicles inside the gels. The proliferation of isolated human follicles seeded in fibrin clots was assessed by the presence of Ki67, which is localized in the nucleus and associated with cell proliferation. A rabbit anti-human Ki67 was used as the primary antibody (dilution 1/400, ref. RM-9106-S, ThermoFisher Scientific, France), and a mice anti-rabbit antibody from the same kit was used as a secondary antibody. Human fetal thymus obtained from our laboratory was used as a positive control, and the negative control consisted of buffer without primary antibody. The expression of Ki67 was characterized by a nuclear brown staining, and the slides were counterstained with anilin blue (ThermoFisher Scientific, France). Follicles were classified into two categories: non-growing follicles when all granulosa cells were Ki67-negative (blue coloration 
only), and growing follicles when at least one granulosa cell was Ki67-positive (brown coloration) [55].

\section{Multicolor flow cytometry (MFC) analysis}

Markers of our experiments are routinely used in hematology for the diagnosis of leukemia. Eight-color MFC was performed using FACSCanto II $^{\mathrm{m}}$ flow cytometer and FACSDiva ${ }^{\mathrm{Tw}}$ software version 6.1.3 $\left(\mathrm{BD}^{\mathrm{Tm}}\right.$ Biosciences, San Jose, CA, USA). The compensation matrix was set up using compbeads $\odot$ (BD Biosciences) according to the manufacturer's instructions. The same combinations of eight monoclonal antibodies were applied to ovarian cell suspensions and to different leukemic cell dilutions in ovarian cell suspensions.

MFC gating strategy was based on previous studies from our team [15-17]. Briefly, our gating strategy was based on the elimination of debris using forward (FSC) and side (SSC) light scatter characteristics. Nucleated viable cells were selected by their $\mathrm{SYTO}^{+} / 7-\mathrm{AAD}^{-}$phenotype. Within these cells, we identified the CD45 $5_{\text {low }}$ population, which corresponds to ovarian and leukemic cells.

The antibody panel included fixed monoclonal antibodies: 7-AAD (Beckman Coulter, France) and SYTO13 (Invitrogen, France) to gate the living nucleated cells as described below and CD45 V500 (Horizon 500, HI30; BD Biosciences) and CD3 V450 (Horizon 450; UCHT1; $\mathrm{BD}$ Biosciences) to characterize $\mathrm{T}$ lymphocytes (CD45 $\left.{ }^{+} / \mathrm{CD}^{+}\right)$. The antibody panel also included variable monoclonal antibodies expressed on leukemic cells at diagnosis (LAIP) coupled: with phycoerythrin (PE), against the antigens CD33 (P67.6; BD Biosciences), or CD44 (515; BD Biosciences), or CD58 (AICD58; Beckman Coulter), or CD361 (MEM-216; Exbio); with allophycocyanin (APC), against CD10 (HI10A; Beckman Coulter), or CLEC 12A (50C1; BD Biosciences), or CD117 (104D2; BD Biosciences); with allophycocyanin H7 (APC-H7), against CD43 (1G10; BD Biosciences), or HLA DR (G46-6; BD Biosciences); with phycoerythrincyanin 7 (PC7), against CD19 (J3.119; Beckman Coulter), or CD34 (581; Beckman Coulter); with V450 and Brillant Violet 421, against CD38 (HB7; BD Biosciences).

Antibodies were added to the cell suspension in $100 \mu \mathrm{l}$ RPMI 1640 GlutaMax (Invitrogen, France) supplemented with $10 \%$ fetal bovine serum (PAN Biotech $\mathrm{GmbH}$, Aidenbach, Germany) and incubated for $20 \mathrm{~min}$ at $+4{ }^{\circ} \mathrm{C}$. After being washed in PBS 1X, cells were resuspended in $100 \mu$ of PBS 1X for MFC analysis.

A cell population was considered abnormal or positive when a homogeneous cluster of at least 20 events expressing the same LAIP as leukemic cells at diagnosis was detected [50]. When less than 20 events were detected by MFC, ovarian suspensions were considered negative or free of a significant number of malignant cells.

\section{Statistical analysis}

Graphpad $^{\text {Tw }}$ software was used for all statistical analysis. Student's $t$ test was used to compare the number of isolated follicles obtained after the dissociation with the GMP grade collagenase NB6, collagenase IA and Liberase DH. The Mann Whitney test was applied to compare the mean diameter of the follicles isolated from each enzyme used for ovarian tissue dissociation and to compare the mean diameter of isolated follicles after short-term in vitro culture. The comparison of the percentages of viable isolated follicles obtained with each enzyme was done using a chi-square test. Results were considered statistically significant when $p \leq 0.05$.

\section{Results}

Evaluation of the GMP Collagenase NB6 for the isolation of human ovarian follicles

\section{Follicle counting and classification}

A total of 2674 follicles were isolated during our experiments ( $n=31$ cortical fragments). In order to validate our isolation technique, we first compared collagenase IA, which was previously used by our team, to collagenase NB6, which can be used in the clinic using the same concentration and incubation time. A total of 1361 (mean $=210 \pm 205$ for $100 \mathrm{mg}$ of tissue; $n=13$ ) follicles were isolated using the GMP grade collagenase NB6, and 1076 (mean = $127 \pm 99$ for $100 \mathrm{mg}$ of tissue; $n=13$ ) using collagenase IA. No significant difference was observed between the two enzymes concerning the number of follicles isolated $(p=0.171)$.

We then compared the follicles obtained after using collagenase NB6, collagenase IA and Liberase DH (Liberase DH has already been validated to isolate human follicles). A total of 532 (mean = 106 \pm 97 for $100 \mathrm{mg}$ of tissue; $n=5$ ) follicles were isolated using the GMP grade collagenase NB6; 406 follicles (mean $=81 \pm 68$ for $100 \mathrm{mg}$ of tissue; $n=$ 5) were isolated with collagenase IA; and 327 follicles (mean $=65 \pm 95$ for $100 \mathrm{mg}$ of tissue; $n=5$ ) with Liberase DH. No significant differences were observed between the three enzymes concerning the number of follicles isolated $(p=0.386$ for Liberase DH versus collagenase NB6; $p=$ 0.720 for Liberase DH versus collagenase IA).

Isolated follicles were classified according to their stage for each isolation protocol. Most of the isolated follicles observed were primordial follicles no matter which enzyme was used: the rate of primordial follicles was $77.5 \%(n=$ 247/319) for collagenase IA, $83.7 \%(n=303 / 362$ isolated follicles) with collagenase NB6 and 75.1\% ( $n=154 / 205$ isolated follicles) with Liberase DH. Isolation with Liberase DH yielded a higher rate of secondary follicles $(10.3 \% ; n=$ 21/205 isolated follicles) (Table 1).

The mean diameter of follicles was evaluated on 781 isolated follicles. Their average diameter was significantly lower when they were isolated with collagenase NB6 (mean 
Table 1 Classification of isolated follicles per protocol after enzymatic dissociation of ovarian cortical strips

\begin{tabular}{lllll}
\hline & Follicles (n) & Primordial (\%) & Primary (\%) & Secondary (\%) \\
\hline Collagenase IA (200 IU/ml) & 319 & $247(77.5)$ & $55(17.2)$ & $17(5.3)$ \\
Collagenase NB6 (200 IU/ml) & 362 & $303(83.7)$ & $48(13.3)$ & $11(3)$ \\
Liberase DH (0.28 Wünsch U/ml) & 205 & $154(75.1)$ & $30(14.6)$ & $21(10.3)$ \\
\hline
\end{tabular}

$\%=$ percentage of each follicular stage out of the total isolated follicles per protocol

$=31.66 \pm 6.79 \mu \mathrm{m} ; n=317$ follicles) when compared to collagenase IA (mean $=36.77 \pm 7.69 \mu \mathrm{m} ; n=273$ follicles) $(p<0.0001)$, and also in comparison with Liberase $\mathrm{DH}$ (mean $=45.21 \pm 8.26 \mu \mathrm{m} ; n=191$ follicles) $(\mathrm{p}<0.0001)$.

\section{Assessment of isolated follicle viability}

Trypan blue staining was first used to assess the initial quality of isolated follicles. No significant differences were observed between trypan blue staining and the live/dead viability assay to determine the survival rate of isolated follicles ( $p=0.99 ; n=76$ follicles analyzed).

After dissociation with collagenase NB6, 93.4\% of the isolated follicles $(n=254 / 272$ isolated follicles $)$ were undamaged or minimally damaged $(\mathrm{V} 1+\mathrm{V} 2)$. The survival rate of follicles isolated with collagenase IA was 92.6\% ( $n=276 / 298$ isolated follicles). After using Liberase $\mathrm{DH}$, the percentage of viable isolated follicles was $94.9 \%$ ( $n=188 / 198$ isolated follicles) (Table 2 ).

There was no significant difference in terms of viability between the three isolation protocols ( $p=0.959$ for collagenase NB6 versus collagenase IA; $p=0.877$ for collagenase NB6 versus Liberase DH; $p=0.728$ for Liberase $\mathrm{DH}$ versus collagenase IA). However, more debris (stained in red by ethidium homodimer-1) were found when using collagenase IA (Fig. 1c and $\mathrm{f}$ ).

In vitro culture of human ovarian follicles isolated with GMP grade collagenase NB6

\section{Follicle proliferation before and after in vitro culture in a} fibrin scaffold

The proliferative status of isolated preantral follicles was assessed after they were seeded inside a fibrin scaffold (Fig. 2). The mean rate of isolated follicles with Ki67positive granulosa cells was $29 \pm 9.19 \%(n=9 / 31$ follicles analyzed). Among the growing follicles, $23 \pm 1.43 \%$ were small secondary follicles $(n=7 / 12$ secondary follicles

Table 2 Viability of isolated follicles after dissociation of ovarian cortical strips

\begin{tabular}{llllll}
\hline & Follicles (n) & V1 & V2 & V3 & V4 \\
\hline Collagenase IA (200 IU/ml) & 298 & 191 & 85 & 17 & 5 \\
Collagenase NB6 (200 IU/ml) & 272 & 194 & 60 & 14 & 4 \\
Liberase DH (0.28 Wünsch U/ml) & 198 & 145 & 43 & 10 & 0 \\
\hline
\end{tabular}

Viability from V1 to V4, using collagenase IA ( $n=7$ patients), collagenase NB6 ( $n=6$ patients), and Liberase $\mathrm{DH}$ ( $n=5$ patients), according to the number of dead granulosa cells analyzed), and $6 \pm 6.36 \%$ represented primary follicles ( $n=2 / 13$ primary follicles analyzed). No primordial follicles were Ki67-positive ( $n=6$ primordial follicles).

After 3 days of in vitro culture, $45 \pm 1.41 \%$ of isolated follicles were Ki67-positive, or growing follicles $(n=10 / 22$ follicles analyzed). Among them, $36 \pm 2.83 \%$ were secondary follicles ( $n=8 / 12$ secondary follicles analyzed), $9 \pm$ $1.41 \%$ were primary follicles $(n=2 / 6$ primary follicles analyzed) and none of them were primordial follicles. All primordial follicles were Ki67-negative $(n=4$ primordial follicles) (Fig. 3).

\section{Assessment of isolated follicle viability}

After 3 days of in vitro culture, the recovery rate of isolated follicles was $69 \%$. Indeed, a total of 456 follicles (range: 36-136 follicles) were embedded in fibrin matrices after their isolation with collagenase NB6, whereas 293 embedded follicles (range: 11-81 follicles) were found after 3 days of short-term in vitro culture. The viability was assessed on fibrin scaffolds containing isolated follicles after 3 days of in vitro culture: we found that $90.7 \%$ of the isolated follicles $(n=307 / 339$ follicles) were undamaged $(76 \%$ of V1) or minimally damaged (15\% of V2) (Table 3 ).

In order to evaluate the follicular growth, all the follicles cultured were analyzed right after embedding them in fibrin gels and 3 days after their in vitro culture. At day 0, the mean diameter of follicles was $47.64 \pm$ $5.99 \mu \mathrm{m}$ ( $n=453$ follicles in 9 fibrin scaffolds). After 3 days of in vitro culture in a fibrin-based scaffold, the mean diameter of follicles significantly increased and was $55.64 \pm 9.89 \mu \mathrm{m}(n=263$ follicles in 9 fibrin scaffolds $(p=0.030)$. At day 3 , two significantly different populations of follicles were observed $(p<0.0001)$ (Fig. 4). Indeed, 37.6\% ( mean $=30.15 \pm 5.02 \mu \mathrm{m}$; 99/263 follicles) of the isolated follicles had a diameter less than or equal to $42 \mu \mathrm{m}$, whereas $62.4 \% \quad$ (mean $=63.11 \pm$ $18.78 \mu \mathrm{m} ; 164 / 263$ follicles) had a diameter greater than $42 \mu \mathrm{m}$ (Fig. 4). Modelization: addition of leukemic cells in human ovarian
cell suspensions and isolation of preantral follicles
An excess of leukemic cells was added to the cell suspension obtained after dissociation of ovarian cortical strips by the GMP grade collagenase NB6. We chose to use collagenase NB6 in the following experiments, because its 

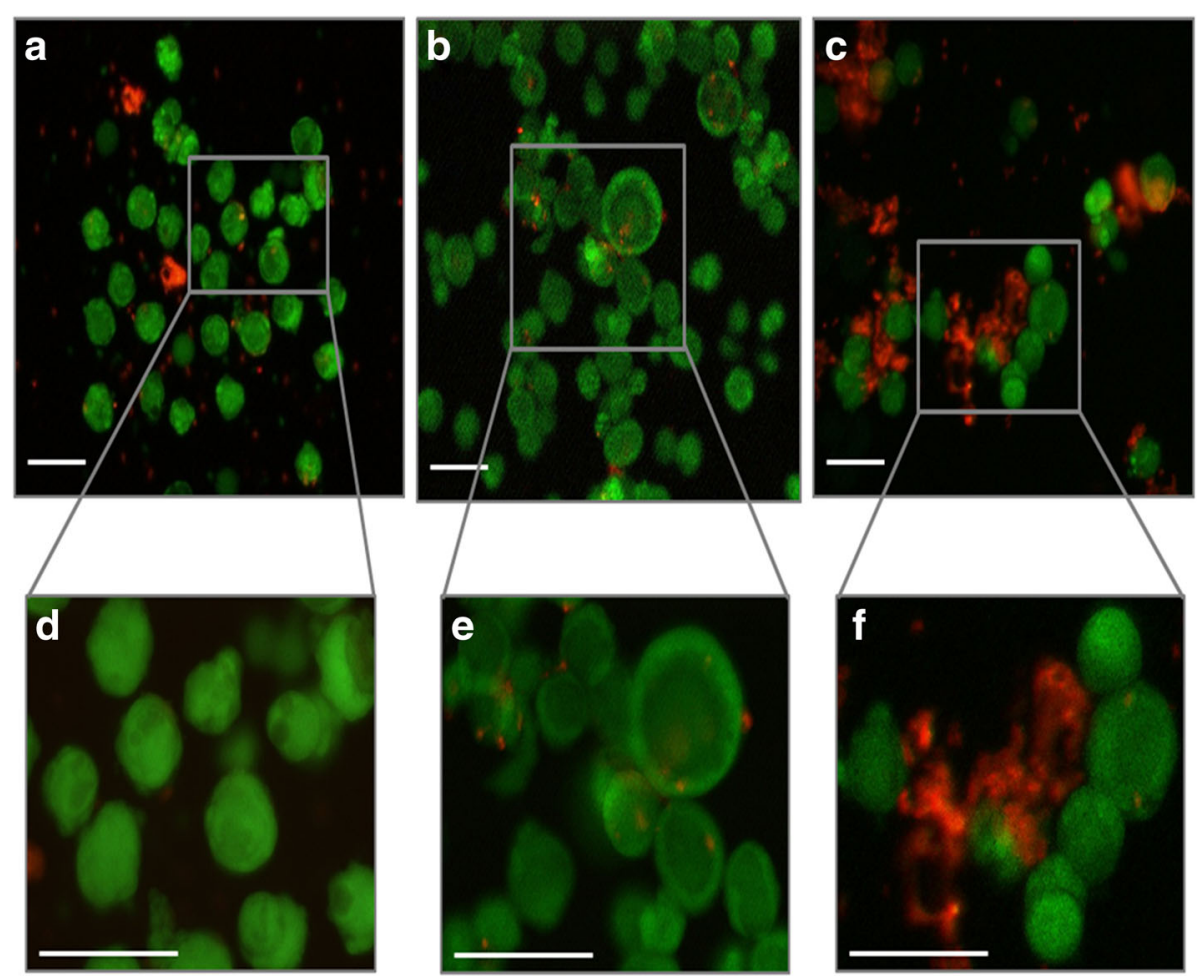

Fig. 1 Viability assay performed on isolated follicles using the fluorescent probes calcein AM and ethidium homodimer-1. a and d. Isolated follicles after using collagenase NB6; $\mathbf{b}$ and e. Isolated follicles after using Liberase $\mathrm{DH} ; \mathbf{c}$ and $\mathbf{f}$. Isolated follicles after using collagenase IA; green: live follicles; red: dead follicles; scale bar $=100 \mu \mathrm{m}$

GMP grade makes it usable in the clinic and also because it generates less debris, as previously observed (Fig. 1). A total of 1068 follicles were picked up during leukemic cell addition in healthy ovarian cell suspensions (Fig. 5a-b). Leukemic cells may adhere to isolated follicles, but after three washes only rare leukemic cells were observed under inverted microscope (Fig. 5c). Observation of ovarian follicular suspensions after 3 washes under an inverted fluorescence microscope confirmed that leukemic cells were mostly eliminated by the process (Fig. $5 \mathrm{~d}-\mathrm{e}$ ).

The number of leukemic cells present in ovarian cell suspensions was evaluated by MFC. In the positive
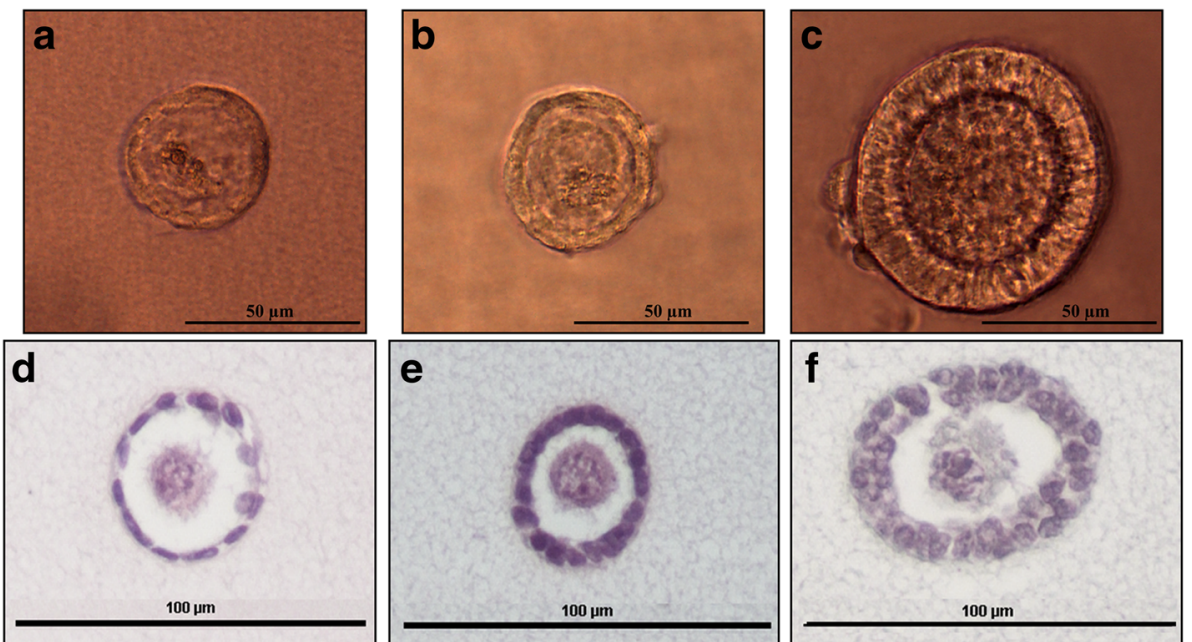

Fig. 2 Isolated preantral follicles embedded in a fibrin scaffold. Brightfield images of an isolated primordial (a), primary (b) and secondary (c) follicle inside a fibrin scaffold; Hematoxylin and eosin staining of an isolated primordial (d), primary (e) and secondary ( $\mathbf{f}$ ) follicle inside a fibrin scaffold 

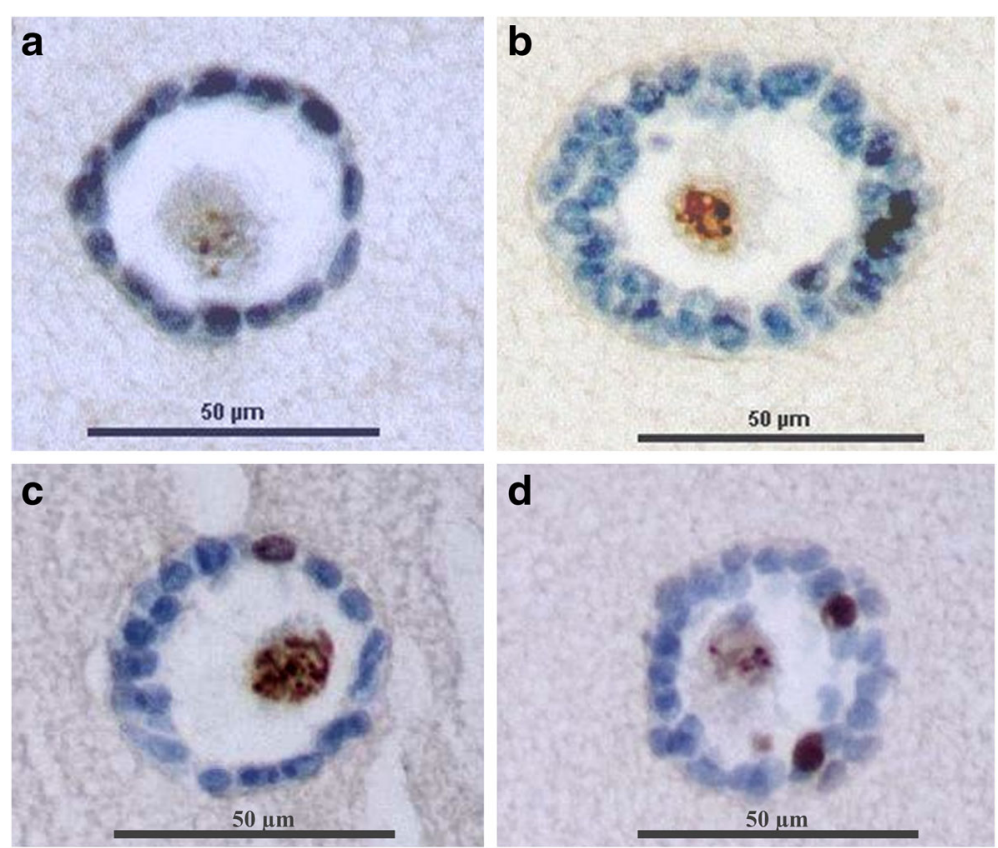

Fig. 3 Immunohistochemistry of isolated preantral follicles embedded in a fibrin scaffold. a Embedded isolated primordial follicle with Ki67negative granulosa cells in blue; $\mathbf{b}$ Embedded isolated secondary follicle with Ki67-negative granulosa cells in blue; $\mathbf{c}$ Embedded isolated primary follicles with one Ki67-positive granulosa cell in brown; d Embedded isolated secondary follicles with two Ki67-positive granulosa cells in brown

control, the cluster of leukemic cells was homogeneous and easily detectable (Fig. 6a). After adding leukemic cells to the ovarian cell suspensions, the number of events detected was low after the first follicle pickup without wash (Fig. 6b), and drastically lower after three washes, even when adding $10^{6}$ leukemic cells (Fig. 6c).

A total of 19,015 leukemic cells (mean $=792 \pm 1402$ leukemic cells; $\min =1 ; \max =4889$ ) were detected before any wash, whereas only 61 leukemic cells (mean $=3 \pm 5$ leukemic cells; $\min =0 ; \max =22$ ) were found

Table 3 Viability of isolated follicles in fibrin scaffolds after 3 days of in vitro culture

\begin{tabular}{lllll}
\hline $\begin{array}{l}\text { Jumber of fibrin gels } \\
(n=9)\end{array}$ & $\mathrm{V} 1$ & $\mathrm{~V} 2$ & $\mathrm{~V} 3$ & $\mathrm{~V} 4$ \\
\hline 1 & 10 & 1 & 0 & 0 \\
2 & 35 & 5 & 2 & 1 \\
3 & 25 & 7 & 5 & 2 \\
4 & 24 & 5 & 3 & 2 \\
5 & 18 & 11 & 3 & 1 \\
6 & 46 & 8 & 2 & 0 \\
7 & 38 & 7 & 1 & 0 \\
8 & 33 & 2 & 2 & 1 \\
9 & 27 & 5 & 7 & 0 \\
Total & 256 & 51 & 25 & 7 \\
\hline
\end{tabular}

after 3 washes, no matter the dilution, across the 24 experiments ( $n=1068$ washed follicles).

Among the 24 experiments, only one cell suspension was positive after 3 washes in IVF medium with 22 events detected, and 23 ovarian cell suspensions were negative (Table 3). When 1 million leukemic cells were added to ovarian cell suspensions, a mean of $2042 \pm 1885$ events corresponding to leukemic cells were detected before any wash $(\min =7 ; \max =4889$; $n=8$ cell suspensions analyzed), whereas only a mean of $5 \pm 7$ events were detected after 3 washes $(\min =0$; $\max =22 ; n=8$ cell suspensions analyzed). For $10^{5}$ leukemic cells added, we found a mean of $316 \pm 420$ events corresponding to leukemic cells before any wash $(\min =1 ; \quad \max =1265 ; n=8$ cell suspensions analyzed) and a mean of $2 \pm 2$ events after 3 washes ( $\min =0 ; \max =4 ; n=8$ cell suspensions analyzed). Finally, for the lowest concentration of leukemic cells $\left(10^{4}\right)$, a mean of $19 \pm 15$ events was detected before any wash $(\min =1 ; \max =37 ; n=8$ cell suspensions analyzed) compared to a mean of $1 \pm 1$ events after 3 washes $(\min =0 ; \quad \max =2 ; \quad n=8$ cell suspensions analyzed) (Table 4).

In order to see the impact of follicle pickup and washes on follicle survival, we evaluated the viability of 323 isolated follicles after three washes according to the classification V1 to V4, using the calcein AM/ethidium homodimer-1 viability assay. The viability of isolated follicles after undergoing three washes was $97.2 \%(n=314 / 323)$ (Table 5). 


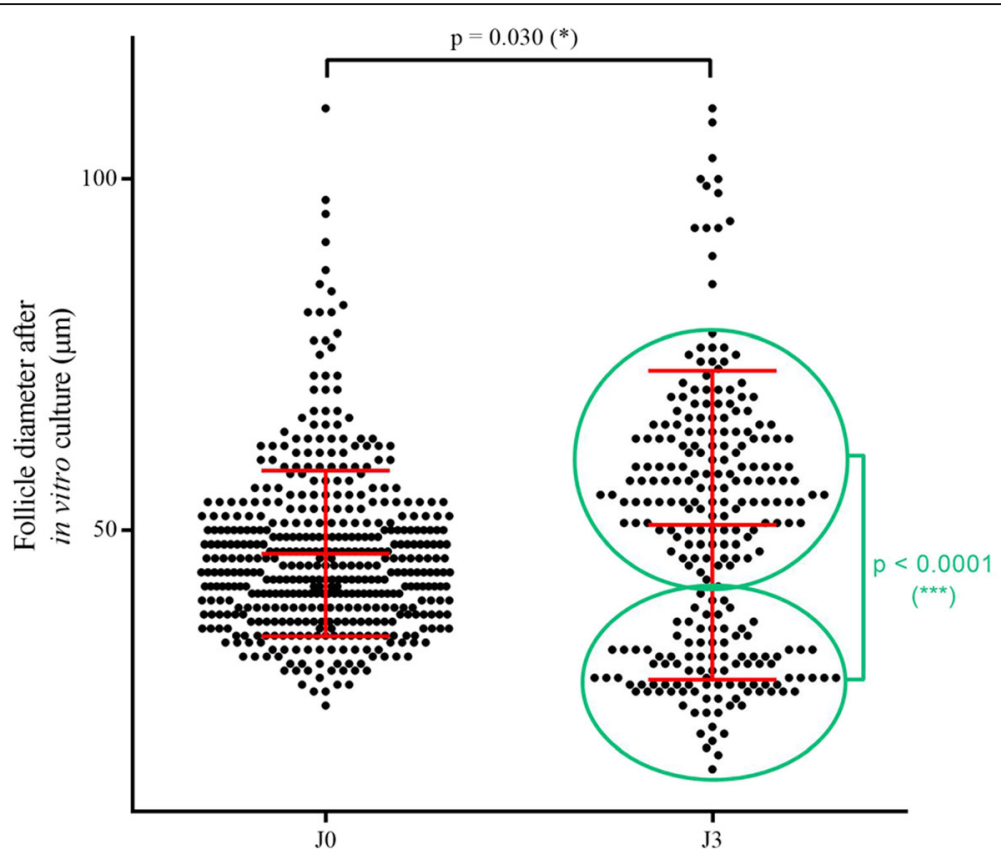

Fig. 4 Follicle diameter before and after 3 days of short-term in vitro culture in a fibrin gel. Dots represent each embedded follicles measured. * = statistically significant

\section{Discussion}

The lifespan of women suffering from cancer continues to increase thanks to the curative treatments currently available. However, it is also well-known that cancer treatments are often associated with decreased quality of life, for instance sexual dysfunction $[56,57]$ and psychosocial disease [58, 59], such as anxiety and depression [60]. Side effects following the administration of therapies may vary according to the type of disease, the type and duration of the treatment, the age of patients and their socioeconomic situation. When the administration of highly gonadotoxic treatments is necessary, techniques such as

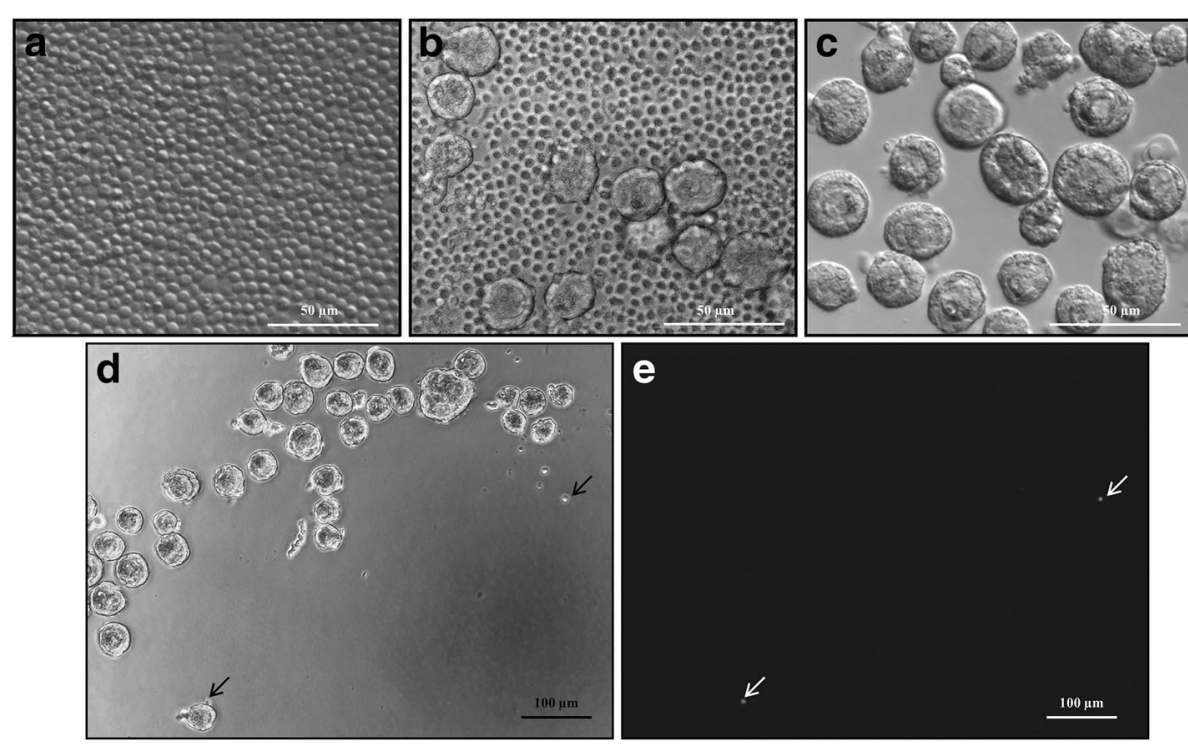

Fig. 5 Cell suspensions observed under an inverted micromanipulation microscope. a Leukemic cell suspension obtained after thawing, corresponding to positive controls; b Ovarian cell suspension, containing follicles and leukemic cells, without wash; c Ovarian cell suspension obtained after 3 washes of isolated follicles; $\mathbf{d}$ An example of ovarian cell suspension obtained after 3 washes of isolated follicles, with two leukemic cells visible (black arrows); e The same ovarian cell suspension obtained after 3 washes under inverted fluorescence microscope, showing the presence of two leukemic cells stained by using a fluorescent cell tracer (white arrows) 

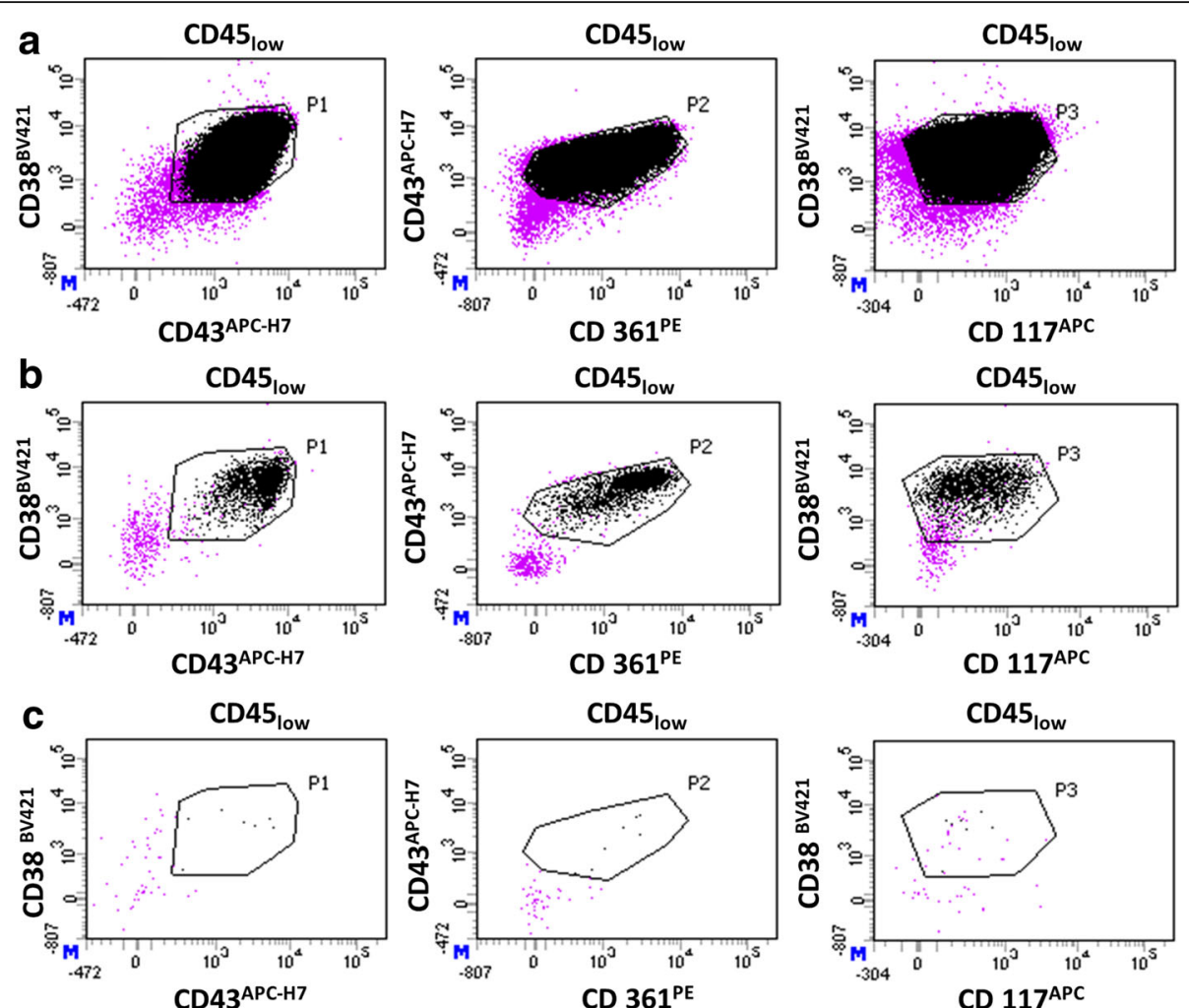

Fig. 6 Quantification of leukemic cells by MFC in an ovarian suspension containing isolated follicles. Only viable nucleated cells (SYTO13 $\left.{ }^{+} / 7-\mathrm{AAD}^{-}\right)$, which are $C D 45$ low were represented (purple dots). Black dots represent leukemic cells detected with a typical immunophenotype $\operatorname{CD} 38^{+} / \mathrm{CD} 43^{+} / \mathrm{CD} 361^{+} / \mathrm{CD} 117^{+}$ among the population of $C D 45_{10 w}$ cells. A positive event must be at the intersection of gates P1 (CD38 versus CD43), P2 (CD43 versus CD361), and P3 (CD38 versus CD117). a Positive control (leukemic cells); b MFC analysis of follicles isolated from healthy ovarian suspension after addition of $10^{6}$ leukemic cells, before any wash ( $n=2069$ events detected); c MFC analysis of isolated follicles after 3 washes $(n=7$ events detected)

oocyte-, embryo- and ovarian tissue cryopreservation are currently available [7]. For some pathologies including endometrial cancer and ovarian cancer, conservative surgery treatments can also be recommended as fertility sparing strategies [61, 62]. It is important to point out that appropriate fertility preservation counseling is primordial in order to offer adequate fertility preservation techniques and to help women overcome this hardship, but is also mandatory in some countries such as France [63]. Fertility preservation counseling is even more important when ovarian tissue transplantation is associated with a high risk of cancer reseeding, and women should be aware when the autograft of their cryopreserved ovarian tissue would be too dangerous.

When the risk of reseeding malignant cells via the ovarian graft is too high, the transplantation of isolated preantral follicles may be one of the best feasible alternatives. Protocols used for the isolation of preantral follicles can have an impact on their survival, function and morphological integrity $[46,64]$. Our study is the first to validate the efficiency of the purified GMP grade collagenase NB6 to successfully isolate a significant number of viable human ovarian follicles.
No significant differences were found between Liberase DH, collagenase IA and the GMP grade collagenase NB6 in terms of yield. However, ovarian suspensions obtained after using GMP grade collagenase NB6 and Liberase DH were less contaminated with undesirable components such as dead cell fragments and conjunctive debris. These components, still present if the digestion is not complete, can stick to isolated follicles, tending to make the follicle isolation process longer and more difficult. The possibility that some follicles observed under the stereomicroscope were actually created by their association with debris and thus creating a heap of extracellular matrix components cannot be excluded in this case.

The mean diameter of follicles isolated with collagenase NB6 was close to results obtained in a study comparing Liberase DH and collagenase IA [43]. Diameters of isolated follicles in our study were significantly lower with collagenases IA and NB6 in comparison to Liberase DH. This might be explained by the additional filtration step used in our procedure to collect follicles of less than $60 \mu \mathrm{m}$ after the dissociation, contrary to the protocol used for Liberase DH. 
Table 4 Results obtained after analysis by MFC of the isolated follicle suspensions after adding leukemic cells

\begin{tabular}{|c|c|c|c|c|c|c|c|c|}
\hline \multirow[b]{3}{*}{ Patients } & \multirow[b]{3}{*}{$\begin{array}{l}\text { Cortical biopsie } \\
\text { weight (mg) }\end{array}$} & \multirow[b]{3}{*}{$\begin{array}{l}\text { Number of } \\
\text { isolated follicles }\end{array}$} & \multirow[b]{3}{*}{$\begin{array}{l}\text { Number of added } \\
\text { leukemic cells }\end{array}$} & \multirow[b]{3}{*}{$\begin{array}{l}\text { Type of } \\
\text { leukemia }\end{array}$} & \multicolumn{4}{|l|}{ MFC } \\
\hline & & & & & \multicolumn{2}{|c|}{$\begin{array}{l}\text { Number of leukemic } \\
\text { cells detected }\end{array}$} & \multicolumn{2}{|l|}{ Results } \\
\hline & & & & & $\begin{array}{l}\text { Before } \\
\text { wash }\end{array}$ & $\begin{array}{l}\text { After } 3 \\
\text { washes }\end{array}$ & $\begin{array}{l}\text { Before } \\
\text { wash }\end{array}$ & $\begin{array}{l}\text { After } 3 \\
\text { washes }\end{array}$ \\
\hline 1 & 46.2 & 93 & $1.10^{6}$ & B-ALL & 4889 & 0 & POSITIVE & NEGATIVE \\
\hline 1 & 46.2 & 89 & $1.10^{5}$ & B-ALL & 452 & 4 & POSITIVE & NEGATIVE \\
\hline 1 & 46.2 & 91 & $1.10^{4}$ & B-ALL & 32 & 0 & POSITIVE & NEGATIVE \\
\hline 2 & 69.6 & 4 & $1.10^{6}$ & B-ALL & 7 & 0 & NEGATIVE & NEGATIVE \\
\hline 2 & 69.6 & 10 & $1.10^{5}$ & B-ALL & 6 & 0 & NEGATIVE & NEGATIVE \\
\hline 2 & 69.6 & 17 & $1.10^{4}$ & B-ALL & 1 & 0 & NEGATIVE & NEGATIVE \\
\hline 3 & 77 & 50 & $1.10^{5}$ & $\mathrm{AML}$ & 15 & 3 & NEGATIVE & NEGATIVE \\
\hline 3 & 77 & 35 & $1.10^{4}$ & AML & 1 & 0 & NEGATIVE & NEGATIVE \\
\hline 3 & 77 & 31 & $1.10^{3}$ & AML & 3 & 0 & NEGATIVE & NEGATIVE \\
\hline 4 & 70.9 & 11 & $1.10^{6}$ & AML & 177 & 4 & POSITIVE & NEGATIVE \\
\hline 4 & 70.9 & 5 & $1.10^{5}$ & AML & 11 & 1 & NEGATIVE & NEGATIVE \\
\hline 4 & 70.9 & 3 & $1.10^{4}$ & AML & 3 & 0 & NEGATIVE & NEGATIVE \\
\hline 5 & 31.7 & 47 & $1.10^{6}$ & AML & 3434 & 22 & POSITIVE & POSITIVE \\
\hline 5 & 31.7 & 46 & $1.10^{5}$ & AML & 388 & 3 & POSITIVE & NEGATIVE \\
\hline 5 & 31.7 & 36 & $1.10^{4}$ & AML & 37 & 2 & POSITIVE & NEGATIVE \\
\hline 6 & 59.3 & 88 & $1.10^{6}$ & AML & 3799 & 6 & POSITIVE & NEGATIVE \\
\hline 6 & 59.3 & 96 & $1.10^{5}$ & AML & 1265 & 3 & POSITIVE & NEGATIVE \\
\hline 6 & 59.3 & 65 & $1.10^{4}$ & AML & 36 & 1 & POSITIVE & NEGATIVE \\
\hline 7 & 38.6 & 12 & $1.10^{6}$ & AML & 2069 & 7 & POSITIVE & NEGATIVE \\
\hline 7 & 38.6 & 20 & $1.10^{5}$ & AML & 206 & 2 & POSITIVE & NEGATIVE \\
\hline 7 & 38.6 & 16 & $1.10^{4}$ & AML & 25 & 2 & POSITIVE & NEGATIVE \\
\hline 8 & 38.6 & 63 & $1.10^{6}$ & AML & 1942 & 1 & POSITIVE & NEGATIVE \\
\hline 8 & 38.6 & 68 & $1.10^{5}$ & AML & 202 & 0 & POSITIVE & NEGATIVE \\
\hline 8 & 38.6 & 72 & $1.10^{4}$ & AML & 15 & 0 & NEGATIVE & NEGATIVE \\
\hline Total & & 1068 & & & 19,015 & 61 & & \\
\hline Mean & & & & & 792 & 3 & & \\
\hline Standard deviation & & & & & 1402 & 5 & & \\
\hline Number of experiments & 24 & & & & & & & \\
\hline
\end{tabular}

Results obtained before and after three washes of 24 ovarian suspensions containing isolated follicles, in which serial dilutions of leukemic cells (from $10^{3}$ to $10^{6}$ ) were artificially added

Table 5 Viability of isolated follicles after three washes

\begin{tabular}{lllll}
\hline Number of experiments & V1 & V2 & V3 & V4 \\
\hline 1 & 21 & 10 & 2 & 0 \\
2 & 16 & 7 & 3 & 0 \\
3 & 20 & 15 & 0 & 0 \\
4 & 60 & 8 & 3 & 0 \\
5 & 52 & 5 & 1 & 0 \\
6 & 92 & 8 & 0 & 0 \\
Total & 261 & 53 & 9 & 0 \\
\hline
\end{tabular}

$n=6$ ovarian strips
The survival rate of isolated follicles was very high in all cases after the dissociation technique, which is in agreement with other studies aiming to isolate human preantral follicles [42, 43, 46, 65].

Ki67 analysis showed that the majority of isolated follicles analyzed after using collagenase NB6 contained Ki67negative granulosa cells. Even after 3 days of in vitro culture, less than $50 \%$ of follicles were non-growing. This shows that most of the isolated follicles were not activated following dissociation with the GMP grade collagenase NB6. Growing follicles (Ki67-positive) were mostly secondary follicles, probably due to their initial development before the dissociation step. The GMP grade collagenase 
NB6 should not activate the growth of preantral follicles and therefore does not alter their initial condition before their transplantation in leukemia patients.

Indeed we did not observe a high growth of human isolated follicles as seen in other studies performed for 7 days $[53,66,67]$, but the time required to initiate their growth must be longer to allow them to fully benefit from the nutrients present in their culture environment. After only 3 days of in vitro culture, we started to observe a heterogeneous distribution of isolated follicles, reflecting the presence of two distinct populations.

According to our results concerning the proliferation of cultured follicles, we can hypothesize that the population of isolated follicles with a diameter below $42 \mu \mathrm{m}$ must be non-growing follicles still quiescent in the fibrin matrix; whereas the second population with a higher diameter may correspond to activated follicles that have started their development. A longer culture duration of 7 days or more should be done to check this hypothesis and see if more growing follicles (Ki67-positive) would be found.

Small isolated follicles, mostly primordial and primary follicles obtained after dissociation of thawed human ovarian cortical pieces are fragile, so they can rapidly deteriorate in culture even if a large number are viable soon after their isolation [64]. After 3 days of in vitro culture, isolated follicles succeeded in maintaining a high viability, of more than $90 \%$, supporting the idea that the use of GMP grade collagenase NB6 is safe for the isolation of human ovarian preantral follicles.

The fibrin formulation previously used by Paulini et al. [53] was sufficient to produce a scaffold able to support and maintain the 3D structure of human follicles up to 3 days in vitro. However, after this period, we observed a degradation of the matrix around some follicles and a loss of follicles (data not shown). It has already been described in the literature that fibrin clots tend to shrink and degrade after in vitro culture due to fibrinolysis induced by the production of plasminogen activators and connective tissue growth factors by granulosa cells [68-70]. To inhibit this process, other components like aprotinin have been added to the culture media [71]. However, the aim of our study was not to perform an in vitro folliculogenesis but to evaluate the effect of a new GMP grade collagenase on human isolated follicles. This is why we did not extend the culture longer than 3 days, especially as this period was sufficient to evaluate the harmlessness of the GMP grade collagenase NB6.

For clinical purposes, in cases of cancer where the risk of malignant cell contamination is high, it is now clear that new protocols aiming at "isolating human ovarian follicles should include an additional step to confirm the absence of malignant cells in the follicular suspension" as suggested by Amorim and Shikanov [72]. After the validation of our isolation technique, we wanted to ensure the safety of the procedure by adding frozen/ thawed malignant cells obtained from AML and ALL patients in healthy ovarian cell suspensions. The possibility of purging the entire ovarian suspensions using a fluorescent labelling system with antibodies specific to malignant cells has been investigated [73]. However, even though it is efficient, this method can be timeconsuming and for now these devices cannot be sterilized for re-use in clinics. Soares et al. have demonstrated the safety of their isolation process after the dissociation of artificially contaminated human ovarian tissue from healthy women [42] and from leukemia patients [74], by using RT-qPCR and fluorescence microscopy to detect the presence of leukemic cells in ovarian suspensions. Contrary to their study, we used the technique of MFC, which we have previously codified, as a detection technique to assess the number of living leukemic cells present in ovarian suspensions obtained after the dissociation of human cryopreserved cortical strips [17].

Even though the theoretical number of leukemic cells potentially present in a fragment has been estimated based on biopsy volume and average volume density of blood vessels in the ovarian cortex [42, 75], we cannot accurately state how many cancer cells would be present in cryopreserved ovarian tissue from leukemia patients. To ensure that we were able to eliminate leukemic cells in any case, we decided to add an excess of $10^{3}$ to $10^{6}$ leukemic cells in healthy ovarian suspensions containing isolated follicles. The quantity of malignant cells present in ovarian tissue from leukemia patients would most likely be lower than the number of leukemic cells added in the present study, especially as leukemia patients are likely to have already initiated chemotherapy before cryopreservation [11, 17, 76]. However, even though chemotherapy can decrease the presence of leukemic cells, it has been shown that it cannot completely eliminate the risk of contamination $[12,15,49]$.

During the isolation procedure, before any wash, it can be difficult to distinguish leukemic cells from stromal cells. Indeed, as observed by Soares et al., the size of leukemic cells is close to that of stromal cells [42]. Moreover, the diameter of the denudation pipette used for all experiments was large enough to allow the aspiration of debris and leukemic cells during the follicle pickup.

In most of our experiments, the number of leukemic cells present in the ovarian cell suspensions after three washes would not be sufficient to potentially induce a relapse of the disease, as according to the literature, the level of minimal residual disease in blood and bone marrow is considered positive when more than 20 positive events are detected by MFC [50]. In only one 
case in our study, the number of leukemic cells detected was higher than 20 events after three washes. This case corresponded to a suspension in which 1 million leukemic cells were added; knowing that such a high amount of malignant cells would likely not be found in cryopreserved ovarian biopsies from leukemia survivors, these results are quite promising. The viability of isolated follicles was not altered by washes, thereby confirming the harmlessness of the isolation technique.

The major advantage of the MFC strategy is to quantify leukemic cells specifically by differentiating them from ovarian cells and normal lymphocytes that could be present in the ovarian cortex. Nevertheless, it is possible that a few leukemic cells could be undetected by MFC if they are aggregated to isolated follicles. Three washes of the isolated follicles into droplets of fresh in vitro fertilization medium were able to reduce the amount of leukemic cells that could potentially contaminate the ovarian suspension. These results also confirmed the efficiency of MFC to detect leukemic cells among a suspension containing washed human isolated follicles. We would like to insist on the fact that, when molecular markers are not available, MFC is the only technique applicable to quantifying the risk of ovarian residual disease, and so it should be offered to all patients with a risk of leukemia reseeding in the future.

\section{Conclusion}

As a conclusion, we succeeded in codifying a new isolation protocol that allows us to obtain a high number of viable follicles from human ovarian cortex using the highly-purified blend enzyme collagenase NB6 produced in accordance with good manufacturing practices. Indeed, the primordial follicles were maintained in their basement statement. In the majority of cases, three washes of the isolated follicles were sufficient to ensure the subsequent carcinologic safety of the final ovarian suspension. This GMP clinical-grade enzyme, in combination with the present isolation technique, will enable the use of isolated human preantral follicles for future clinical applications.

\section{Abbreviations \\ ALL: Acute lymphoblastic leukemia; AML: Acute myeloid leukemia; BM: Bone marrow; DMSO: Dimethyl sulfoxide; FSC: Forward light scatter; GMP: Good manufacturing practices; ICSI: Intra cytoplasmic sperm injection; ITS: Insulin, transferring, sodium, selenite; IVF: In vitro fertilization; LAIP: Leukemia- associated immunophenotype; MFC: Multicolor flow cytometry; MRD: Minimal residual disease; PBS: Phosphate-buffered saline; RPMI: Roswell park memorial institute; RT-qPCR: Real time quantitative polymerase chain reaction; SSC: Side light scatter; aMEM: alpha-Minimum essential medium}

\section{Acknowledgements}

The authors thank Aurélie BERDIN, MD (Service de GynécologieObstétrique, Centre Hospitalier Universitaire de Besançon) for her help in the ovarian tissue collection, Professor Séverine VALMARY DEGANO (Service d'Anatomie et Cytologie Pathologique, Centre Hospitalier Régional Universitaire de Besançon) for the performance of paraffin blocks and immunocytochemical analyses and Jason SELLERS, medical intern (Bryn Mawr Hospital, Philadelphia) for the language revision.

\section{Funding}

This study was supported by the BioMedicine Agency (Agence de la Biomedecine, 2015 call for tender: assisted reproductive technology, prenatal diagnosis and genetic diagnosis), the Committee of the League against Cancer (Comité de la ligue contre le Cancer, Haut-Rhin, 2011), Besançon University Hospital (APICHU call for tender, Franche-Comté Regional council, 2011) and the DGOS/INSERM/INCa (Appel d'offre Recherche translationnelle 2012). Funding for a doctoral thesis has been awarded by the regional Council of Franche-Comté (Conseil Régional de Franche-Comté, 2014).

\section{Availability of data and materials}

All data generated and analyzed during this study are included in the published article.

\section{Authors' contributions}

EM Study design, experimental procedures, interpretation of results and manuscript preparation. TZ Experimental procedures, statistical analyses and manuscript revision. CR Study design, interpretation of results and manuscript revision. CA Study design, experimental procedures, interpretation of results and manuscript revision. All authors approved the final manuscript.

\section{Ethical approval and consent to participate}

The use of human ovarian tissue was approved by the clinical ethics committee of Besancon University Hospital in 2013; all patients gave their informed consent. The use of leukemic cells from leukemia patients was approved by the department of research and innovation (CRB F.Cabanne, Dijon-Besançon, France; biological collection authorization nDC-2008-713). The use of $A B$ human serum from male donors was approved by the French blood establishment (request of blood samples for non-therapeutic uses, $\mathrm{BFC/PSL/COL/FO/014).}$

Consent for publication

Not applicable.

\section{Competing interests}

The authors declare that they have no competing interests.

\section{Publisher's Note}

Springer Nature remains neutral with regard to jurisdictional claims in published maps and institutional affiliations.

\section{Author details}

${ }^{1}$ University Bourgogne Franche-Comté, INSERM, EFS BFC, UMR1098, Interactions Hôte-Greffon-Tumeur/Ingénierie Cellulaire et Génique, F-25000 Besançon, France. ${ }^{2}$ INSERM CIC-1431, University Hospital of Besançon, Clinical Investigation Center in Biotherapy, F-25000 Besançon, France. ${ }^{3}$ Department of Reproductive Medicine and Biology, Cryobiology, University Hospital of Besançon, 3 boulevard Fleming, 25000 Besançon Cedex, France.

Received: 24 August 2017 Accepted: 26 December 2017

Published online: 05 January 2018

\section{References}

1. Siegel R, Ma J, Zou Z, Jemal A. Cancer statistics, 2014. CA Cancer J Clin. 2014;64(1):9-29.

2. Ward E, DeSantis C, Robbins A, Kohler B, Jemal A. Childhood and adolescent cancer statistics, 2014. CA Cancer J Clin. 2014;64(2):83-103.

3. Imbert R, Moffa F, Tsepelidis S, Simon P, Delbaere A, Devreker F, et al. Safety and usefulness of cryopreservation of ovarian tissue to preserve fertility: a 12-year retrospective analysis. Hum Reprod. 2014;29(9):1931-40.

4. Lee SJ, Schover LR, Partridge AH, Patrizio P, Wallace WH, Hagerty K, et al. American Society of Clinical Oncology recommendations on fertility preservation in cancer patients. J Clin Oncol. 2006;24(18):2917-31.

5. Peddie VL, Porter MA, Barbour R, Culligan D, MacDonald G, King D, et al. Factors affecting decision making about fertility preservation after cancer diagnosis: a qualitative study. BJOG. 2012;119(9):1049-57. 
6. Donnez J, Dolmans MM. Fertility preservation in women. Nat Rev Endocrinol. 2013;9(12):735-49.

7. Donnez J, Dolmans MM. Fertility preservation in women. N Engl J Med. 2017;377(17):1657-65.

8. Jensen AK, Macklon KT, Fedder J, Ernst E, Humaidan P, Andersen CY. 86 successful births and 9 ongoing pregnancies worldwide in women transplanted with frozen-thawed ovarian tissue: focus on birth and perinatal outcome in 40 of these children. J Assist Reprod Genet. 2017:34(3):325-36.

9. Bastings L, Beerendonk CC, Westphal JR, Massuger LF, Kaal SE, van Leeuwen $\mathrm{FE}$, et al. Autotransplantation of cryopreserved ovarian tissue in cancer survivors and the risk of reintroducing malignancy: a systematic review. Hum Reprod Update. 2013;19(5):483-506.

10. Dolmans MM, Luyckx V, Donnez J, Andersen CY, Greve T. Risk of transferring malignant cells with transplanted frozen-thawed ovarian tissue. Fertil Steril. 2013;99(6):1514-22.

11. Dolmans MM, Marinescu C, Saussoy P, Van Langendonckt A, Amorim C, Donnez J. Reimplantation of cryopreserved ovarian tissue from patients with acute lymphoblastic leukemia is potentially unsafe. Blood. 2010; 116(16):2908-14.

12. Greve T, Schmidt KT, Kristensen SG, Ernst E, Andersen CY. Evaluation of the ovarian reserve in women transplanted with frozen and thawed ovarian cortical tissue. Fertil Steril. 2012;97(6):1394-8. e1

13. Meirow D, Biederman $H$, Anderson RA, Wallace WH. Toxicity of chemotherapy and radiation on female reproduction. Clin Obstet Gynecol. 2010;53(4):727-39.

14. Jahnukainen K, Tinkanen H, Wikstrom A, Dunkel L, Saarinen-Pihkala UM, Makinen S, et al. Bone marrow remission status predicts leukemia contamination in ovarian biopsies collected for fertility preservation. Leukemia. 2013;27(5):1183-5.

15. Zver T, Alvergnas-Vieille M, Garnache-Ottou F, Roux C, Amiot C. A new method for evaluating the risk of transferring leukemic cells with transplanted cryopreserved ovarian tissue. J Assist Reprod Genet. 2015;32(8):1263-6.

16. Zver T, Alvergnas-Vieille M, Garnache-Ottou F, Ferrand C, Roux C, Amiot C. Minimal residual disease detection in cryopreserved ovarian tissue by multicolor flow cytometry in acute myeloid leukemia. Haematologica. 2014; 99(12):e249-52.

17. Amiot C, Angelot-Delettre F, Zver T, Alvergnas-Vieille M, Saas P, GarnacheOttou F, et al. Minimal residual disease detection of leukemic cells in ovarian cortex by eight-color flow cytometry. Hum Reprod. 2013;28(8):2157-67.

18. Zver T, Mouloungui E, Berdin A, Roux C, Amiot C. Validation of an automated technique for ovarian cortex dissociation: isolation of viable ovarian cells and their qualification by multicolor flow cytometry. J Ovarian Res. 2017;10(1):38

19. Soares M, Saussoy P, Sahrari K, Amorim CA, Donnez J, Dolmans MM. Is transplantation of a few leukemic cells inside an artificial ovary able to induce leukemia in an experimental model? J Assist Reprod Genet. 2015; 32(4):597-606.

20. Chiti MC, Dolmans MM, Orellana R, Soares M, Paulini F, Donnez J, et al. Influence of follicle stage on artificial ovary outcome using fibrin as a matrix. Hum Reprod. 2016;31(2):427-35.

21. Laronda MM, Jakus AE, Whelan KA, Wertheim JA, Shah RN, Woodruff TK. Initiation of puberty in mice following decellularized ovary transplant. Biomaterials. 2015;50:20-9.

22. Laronda MM, Duncan FE, Hornick JE, Xu M, Pahnke JE, Whelan KA, et al. Alginate encapsulation supports the growth and differentiation of human primordial follicles within ovarian cortical tissue. J Assist Reprod Genet. 2014;31(8):1013-28.

23. Luyckx V, Dolmans MM, Vanacker J, Scalercio SR, Donnez J, Amorim CA. First step in developing a 3D biodegradable fibrin scaffold for an artificial ovary. J Ovarian Res. 2013;6(1):83

24. Luyckx V, Dolmans MM, Vanacker J, Legat C, Fortuno Moya C, Donnez J, et al. A new step toward the artificial ovary: survival and proliferation of isolated murine follicles after autologous transplantation in a fibrin scaffold. Fertil Steril. 2014;101(4):1149-56.

25. Vanacker J, Luyckx V, Dolmans MM, Des Rieux A, Jaeger J, Van Langendonckt $A$, et al. Transplantation of an alginate-matrigel matrix containing isolated ovarian cells: first step in developing a biodegradable scaffold to transplant isolated preantral follicles and ovarian cells. Biomaterials. 2012;33(26):6079-85.

26. Kniazeva E, Hardy AN, Boukaidi SA, Woodruff TK, Jeruss JS, Shea LD. Primordial follicle transplantation within designer biomaterial grafts produce live births in a mouse infertility model. Sci Rep. 2015;5:17709.
27. Laronda MM, Rutz AL, Xiao S, Whelan KA, Duncan FE, Roth EW, et al. A bioprosthetic ovary created using 3D printed microporous scaffolds restores ovarian function in sterilized mice. Nat Commun. 2017;8:15261.

28. Vanacker J, Amorim CA. Alginate: a versatile biomaterial to encapsulate isolated ovarian follicles. Ann Biomed Eng. 2017;45(7):1633-49.

29. Xu J, Lawson MS, Yeoman RR, Molskness TA, Ting AY, Stouffer RL, et al. Fibrin promotes development and function of macaque primary follicles during encapsulated three-dimensional culture. Hum Reprod. 2013;28(8): $2187-200$.

30. Xu J, Xu M, Bernuci MP, Fisher TE, Shea LD, Woodruff TK, et al. Primate follicular development and oocyte maturation in vitro. Adv Exp Med Biol. 2013;761:43-67.

31. Camboni A, Van Langendonckt A, Donnez J, Vanacker J, Dolmans MM, Amorim CA. Alginate beads as a tool to handle, cryopreserve and culture isolated human primordial/primary follicles. Cryobiology. 2013; 67(1):64-9.

32. Hornick JE, Duncan FE, Shea LD, Woodruff TK. Isolated primate primordial follicles require a rigid physical environment to survive and grow in vitro. Hum Reprod. 2012;27(6):1801-10.

33. Barrett SL, Shea LD, Woodruff TK. Noninvasive index of cryorecovery and growth potential for human follicles in vitro. Biol Reprod. 2010;82(6):1180-9.

34. Smitz JE, Cortvrindt RG. The earliest stages of folliculogenesis in vitro. Reproduction. 2002;123(2):185-202.

35. Xu J, Bernuci MP, Lawson MS, Yeoman RR, Fisher TE, Zelinski MB, et al. Survival, growth, and maturation of secondary follicles from prepubertal, young, and older adult rhesus monkeys during encapsulated threedimensional culture: effects of gonadotropins and insulin. Reproduction. 2010;140(5):685-97.

36. Xu M, Barrett SL, West-Farrell E, Kondapalli LA, Kiesewetter SE, Shea LD, et al. In vitro grown human ovarian follicles from cancer patients support oocyte growth. Hum Reprod. 2009;24(10):2531-40.

37. Abir R, Roizman P, Fisch B, Nitke S, Okon E, Orvieto R, et al. Pilot study of isolated early human follicles cultured in collagen gels for 24 hours. Hum Reprod. 1999;14(5):1299-301.

38. Abir R, Fisch B, Nitke S, Okon E, Raz A, Ben RZ. Morphological study of fully and partially isolated early human follicles. Fertil Steril. 2001;75(1):141-6.

39. Yin $H$, Jiang $H$, Kristensen $S G$, Andersen $C Y$. Vitrification of in vitro matured oocytes collected from surplus ovarian medulla tissue resulting from fertility preservation of ovarian cortex tissue. J Assist Reprod Genet. 2016:33(6):741-6.

40. Heeren AM, van Iperen L, Klootwijk DB, de Melo BA, Roost MS, Gomes Fernandes MM, et al. Development of the follicular basement membrane during human gametogenesis and early folliculogenesis. BMC Dev Biol. 2015;15:4.

41. Rodgers RJ, Irving-Rodgers HF, Russell DL. Extracellular matrix of the developing ovarian follicle. Reproduction. 2003;126(4):415-24.

42. Soares M, Sahrari K, Amorim CA, Saussoy P, Donnez J, Dolmans MM Evaluation of a human ovarian follicle isolation technique to obtain disease-free follicle suspensions before safely grafting to cancer patients. Fertil Steril. 2015;104(3):672-80. e2

43. Vanacker J, Camboni A, Dath C, Van Langendonckt A, Dolmans MM, Donnez J, et al. Enzymatic isolation of human primordial and primary ovarian follicles with Liberase $\mathrm{DH}$ : protocol for application in a clinical setting. Fertil Steril. 2011;96(2):379-83. e3

44. Dolmans MM, Michaux N, Camboni A, Martinez-Madrid B, Van Langendonckt A, Nottola SA, et al. Evaluation of Liberase, a purified enzyme blend, for the isolation of human primordial and primary ovarian follicles. Hum Reprod. 2006;21(2):413-20.

45. Chiti MC, Dolmans MM, Hobeika M, Cernogoraz A, Donnez J, Amorim CA. A modified and tailored human follicle isolation procedure improves follicle recovery and survival. J Ovarian Res. 2017;10(1):71.

46. Lierman S, Tilleman K, Cornelissen M, De Vos WH, Weyers S, T'Sjoen G, et al. Follicles of various maturation stages react differently to enzymatic isolation: a comparison of different isolation protocols. Reprod BioMed Online. 2015;30(2):181-90

47. Brandhorst $H$, Friberg A, Nilsson B, Andersson HH, Felldin M, Foss A, et al. Large-scale comparison of Liberase $\mathrm{HI}$ and collagenase NB1 utilized for human islet isolation. Cell Transplant. 2010;19(1):3-8.

48. Fazzina R, Mariotti A, Procoli A, Fioravanti D, ludicone P, Scambia G, et al. A new standardized clinical-grade protocol for banking human umbilical cord tissue cells. Transfusion. 2015;55(12):2864-73. 
49. Soares M, Saussoy P, Maskens M, Reul H, Amorim CA, Donnez J, et al. Eliminating malignant cells from cryopreserved ovarian tissue is possible in leukaemia patients. Br J Haematol. 2017;178(2):231-9.

50. Campana D, Coustan-Smith E. Detection of minimal residual disease in acute leukemia by flow cytometry. Cytometry. 1999;38(4):139-52.

51. Fauque $P$, Ben Amor A, Joanne C, Agnani G, Bresson JL, Roux C. Use of trypan blue staining to assess the quality of ovarian cryopreservation. Fertil Steril. 2007:87(5):1200-7.

52. Roux C, Amiot C, Agnani G, Aubard Y, Rohrlich PS, Piver P. Live birth after ovarian tissue autograft in a patient with sickle cell disease treated by allogeneic bone marrow transplantation. Fertil Steril. 2010; 93(7):2413. e15-9

53. Paulini F, Vilela JM, Chiti MC, Donnez J, Jadoul P, Dolmans MM, et al. Survival and growth of human preantral follicles after cryopreservation of ovarian tissue, follicle isolation and short-term xenografting. Reprod BioMed Online. 2016;33(3):425-32.

54. Martinez-Madrid B, Dolmans MM, Van Langendonckt A, Defrere S, Donnez J. Freeze-thawing intact human ovary with its vascular pedicle with a passive cooling device. Fertil Steril. 2004;82(5):1390-4.

55. Dolmans MM, Yuan WY, Camboni A, Torre A, Van Langendonckt A, Martinez-Madrid B, et al. Development of antral follicles after xenografting of isolated small human preantral follicles. Reprod BioMed Online. 2008;16(5):705-11.

56. Vitale SG, La Rosa VL, Rapisarda AM, Lagana AS. Comment on: "the consequences of gynaecological cancer in patients and their partners from the sexual and psychological perspective". Prz Menopauzalny. 2016;15(3):186-7.

57. Lagana AS, La Rosa VL, Fanale D, Vitale SG. Comment on: survey of cervical cancer survivors regarding quality of life and sexual function. J Cancer Res Ther. 2017;13(3):598-9.

58. Vitale SG, La Rosa VL, Rapisarda AMC, Lagana AS. Fertility preservation in women with gynaecologic cancer: the impact on quality of life and psychological well-being. Hum Fertil (Camb). 2017:1-4. https://doi.org/10. 1080/14647273.2017.1339365

59. Lagana AS, La Rosa VL, Rapisarda AM, Platania A, Vitale SG. Psychological impact of fertility preservation techniques in women with gynaecological cancer. Ecancermedicalscience. 2017;11:ed62.

60. Vitale SG, La Rosa VL, Rapisarda AM, Lagana AS. Comment on: "anxiety and depression in patients with advanced ovarian cancer: a prospective study". J Psychosom Obstet Gynaecol. 2017;38(1):83-4.

61. Vitale SG, Rossetti D, Tropea A, Biondi A, Lagana AS. Fertility sparing surgery for stage IA type I and G2 endometrial cancer in reproductive-aged patients: evidence-based approach and future perspectives. Updat Surg. 2017;69(1):29-34.

62. Chiofalo B, Palmara V, Lagana AS, Triolo O, Vitale SG, Conway F, et al. Fertility sparing strategies in patients affected by placental site Trophoblastic tumor. Curr Treat Options in Oncol. 2017;18(10):58.

63. Vitale SG, La Rosa VL, Rapisarda AMC, Lagana AS. The importance of fertility preservation counseling in patients with gynecologic cancer. J Reprod Infertil. 2017;18(2):261-3.

64. Lenie S, Cortvrindt R, Adriaenssens T, Smitz J. A reproducible two-step culture system for isolated primary mouse ovarian follicles as single functional units. Biol Reprod. 2004;71(5):1730-8.

65. Soares M, Sahrari K, Chiti MC, Amorim CA, Ambroise J, Donnez J, et al. The best source of isolated stromal cells for the artificial ovary: medulla or cortex, cryopreserved or fresh? Hum Reprod. 2015;30(7):1589-98.

66. Vanacker J, Luyckx V, Amorim C, Dolmans MM, Van Langendonckt A, Donnez J, et al. Should we isolate human preantral follicles before or after cryopreservation of ovarian tissue? Fertil Steril. 2013;99(5):1363-8. e2

67. Amorim CA, Van Langendonckt A, David A, Dolmans MM, Donnez J. Survival of human pre-antral follicles after cryopreservation of ovarian tissue, follicular isolation and in vitro culture in a calcium alginate matrix. Hum Reprod. 2009;24(1):92-9.

68. Thorne JT, Segal TR, Chang S, Jorge S, Segars JH, Leppert PC. Dynamic reciprocity between cells and their microenvironment in reproduction. Biol Reprod. 2015;92(1):25.

69. Shikanov A, Zhang Z, Xu M, Smith RM, Rajan A, Woodruff TK, et al. Fibrin encapsulation and vascular endothelial growth factor delivery promotes ovarian graft survival in mice. Tissue Eng Part A. 2011;17(23-24):3095-104.

70. Chiti MC, Dolmans MM, Donnez J, Amorim CA. Fibrin in reproductive tissue engineering: a review on its application as a biomaterial for fertility preservation. Ann Biomed Eng. 2017;45(7):1650-63.
71. Shikanov A, Xu M, Woodruff TK, Shea LD. Interpenetrating fibrin-alginate matrices for in vitro ovarian follicle development. Biomaterials. 2009; 30(29):5476-85.

72. Amorim CA, Shikanov A. The artificial ovary: current status and future perspectives. Future Oncol. 2016;12(20):2323-32.

73. Schroder CP, Timmer-Bosscha H, Wijchman JG, de Leij LF, Hollema H, Heineman MJ, et al. An in vitro model for purging of tumour cells from ovarian tissue. Hum Reprod. 2004;19(5):1069-75.

74. Soares M, Saussoy P, Maskens M, Reul H, Amorim CA, Donnez J, et al. Eliminating malignant cells from cryopreserved ovarian tissue is possible in leukaemia patients. Br J Haematol. 2017. https://doi.org/10.1111/bjh.14657.

75. Delgado-Rosas F, Gaytan M, Morales C, Gomez R, Gaytan F. Superficial ovarian cortex vascularization is inversely related to the follicle reserve in normal cycling ovaries and is increased in polycystic ovary syndrome. Hum Reprod. 2009;24(5):1142-51.

76. Abir R, Ben-Aharon I, Garor R, Yaniv I, Ash S, Stemmer SM, et al. Cryopreservation of in vitro matured oocytes in addition to ovarian tissue freezing for fertility preservation in paediatric female cancer patients before and after cancer therapy. Hum Reprod. 2016;31(4):750-62.

\section{Submit your next manuscript to BioMed Central and we will help you at every step:}

- We accept pre-submission inquiries

- Our selector tool helps you to find the most relevant journal

- We provide round the clock customer support

- Convenient online submission

- Thorough peer review

- Inclusion in PubMed and all major indexing services

- Maximum visibility for your research

Submit your manuscript at www.biomedcentral.com/submit
Biomed Central 